\title{
Mode I and mode II fracture toughness of E-glass non-crimp fabric/carbon nanotube (CNT) modified polymer based composites
}

\author{
A. Tugrul Seyhan ${ }^{a}$, Metin Tanoglu ${ }^{a, *}, K$ Karl Schulte ${ }^{b}$ \\ a Izmir Institute of Technology (IZTECH), Mechanical Engineering Department, Gulbahce Campus, 35437 Izmir, Turkey \\ ${ }^{\mathrm{b}}$ Technicshe Universitat Hamburg-Harburg (TUHH), Institute of Polymers and Composites, Denickestrasse 15, D-21073 Hamburg, Germany
}

\section{A R T I C L E I N F O}

\section{Article history:}

Received 21 April 2008

Received in revised form 12 July 2008

Accepted 5 August 2008

Available online 20 August 2008

\section{Keywords:}

Polymer matrix composites

Toughness testing

Delamination

\begin{abstract}
A B S T R A C T
In this study, mode I and mode II interlaminar fracture toughness, and interlaminar shear strength of E-glass non-crimp fabric/carbon nanotube modified polymer matrix composites were investigated. The matrix resin containing $0.1 \mathrm{wt} . \%$ of amino functionalized multi walled carbon nanotubes were prepared, utilizing the 3-roll milling technique. Composite laminates were manufactured via vacuum assisted resin transfer molding process. Carbon nanotube modified laminates were found to exhibit $8 \%$ and $11 \%$ higher mode II interlaminar fracture toughness and interlaminar shear strength values, respectively, as compared to the base laminates. However, no significant improvement was observed for mode I interlaminar fracture toughness values. Furthermore, Optical microscopy and scanning electron microscopy were utilized to monitor the distribution of carbon nanotubes within the composite microstructure and to examine the fracture surfaces of the failed specimens, respectively.
\end{abstract}

(c) 2008 Elsevier Ltd. All rights reserved.

\section{Introduction}

Fiber reinforced polymer composites have gained substantial attention as structural engineering materials in automotive, marine and aircraft industry as well as in civil engineering applications [1-3]. This interest is due to their outstanding mechanical properties, impact resistance, high durability and flexibility in design capabilities and light weight. These composites have generally good fiber dominated in-plane properties capable of meeting the design requirements for various types of structural applications. However, Z-axis (through the thickness) properties of the composites, such as delamination resistance, have often been far below the expectations due to inadequate performance of the matrix dominated interlaminar region [1-6]. Therefore, in some special applications, these materials may exhibit lower overall structural integrity in accordance with their presumed properties. Delamination has the potential for being the major life limiting failure process. It may even occur during processing of the laminates due to contamination or regions of high void content of prepreg that leads to poor ply adhesion locally [3-7]. In general, delamination corresponds to a crack-like discontinuity between the plies and it may typically extend during application of mechanical or thermal loads or both during service life of composites [4-6]. Fracture toughness of polymer matrix and interfacial shear strength between the matrix and the fiber are of prime importance in monitoring through the thickness properties of the composites. The most common way to improve the delamination resistance of reinforced polymer composites is to incorporate some toughening agents or thermoplastic binders into the brittle matrix resins, such as epoxy, polyester or vinyl ester [2,3]. A treatment of fiber surface with matrix resin compatible sizing is another way to improve the interlaminar strength of the composites by enhancing the interfacial strength between the

\footnotetext{
* Corresponding author. Tel.: +90 232750 7806; fax: +90 2327507890 .

E-mail address: metintanoglu@iyte.edu.tr (M. Tanoglu).
} 
polymer matrix and the fiber. However, some of these modifications induce sometimes a compromise with other mechanical properties.

The incorporation of nano-sized fillers into polymer matrices offers huge potential for the accomplishment of composites with better mechanical properties than those with traditional macro-scale sized fillers. In that manner, carbon nanotubes (CNTs) have gained relatively high interest as alternative filler materials for the modification of polymers, owing to their extraordinary mechanical, thermal and electrical properties, combined with their huge aspect ratio and specific surface area (SSA). Many studies reported in the literature [9-15] revealed that CNT modified resins possessed enhanced mechanical and thermal properties relative to their own base polymer. However, it needs to be emphasized that the corresponding improvements in final properties of CNT modified polymers are still far below the theoretical predictions via conventional composite models. This can be accounted for a strong tendency of CNTs to agglomerate within the polymers arising from their inert and huge surface area, thus leading to non-homogeneous dispersion of CNTs within the surrounding matrix. To enhance their dispersibility within the resin, chemical functional groups compatible with the matrix resin can be grafted onto surfaces of the CNTs [8-11]. Many approaches including direct mixing, high speed mechanical stirring and sonication have been attempted to accomplish the uniform dispersion of carbon nanotubes within liquid resins. Recently, high shear mixing via 3roll milling technique has been reported to be rather effective, thus enabling relatively good dispersion of nanotubes within liquid thermosetting resins [10-18]. Gojny et al. [13] found that 3-roll milling processed epoxy based nanocomposites containing $0.3 \mathrm{wt}$ \% of amino functionalized double walled carbon nanotubes (DWCNT- $\mathrm{NH}_{2}$ ) exhibited $42 \%$ higher fracture toughness values as compared to neat epoxy resin, while retaining their tensile strength and modulus values. In their an-

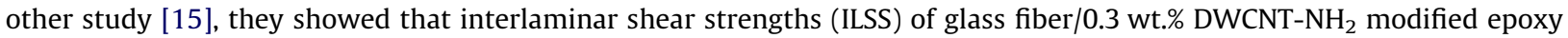
matrix composites is $19 \%$ higher than those of glass fiber/neat epoxy composites. Similar finding was also reported by Wichmann et al. [16] such that the interlaminar strength of glass fiber reinforced composites with nano-particle modified epoxy matrix were significantly improved (16\%) by adding only $0.3 \mathrm{wt}$.\% of DWCNTs. However, they also stated that interlaminar fracture toughness values of the corresponding composites were, astonishingly, not affected in comparable manner. In brief, enhancement in fracture toughness of the matrix resin due to CNTs addition seems beneficial for the improvement of the matrix dominated mechanical properties such as interlaminar shear strength and fracture toughness of their associated long fiber reinforced composites.

In our former studies $[17,18]$, MWCNT- $\mathrm{NH}_{2}$ modified vinyl ester and polyester based nanocomposites were reported to possess higher glass transition temperatures and elastic modulus as compared to neat hybrid resin and the nanocomposites containing the same content of MWCNTs. In a similar manner, it is the aim of this study to demonstrate the extent of enhancement in matrix dominated mechanical properties of glass fiber reinforced composite laminates with $\mathrm{MWCNT}_{\mathrm{N}} \mathrm{NH}_{2}$ modified hybrid resin as matrix material. For this purpose, interlaminar fracture toughness $\left(G_{\text {Ic }}\right.$ and $G_{\text {IIc }}$ ) and the interlaminar shear strength of VARTM processed glass fiber non-crimp fabrics/MWCNT- $\mathrm{NH}_{2}$ modified vinyl ester polyester based composites were investigated in conjunction with the values of the base composite laminates prepared with neat hybrid resin.

\section{Experimental}

\subsection{Materials}

Amino functionalized multi-walled carbon nanotubes (MWCNT-NH $\mathrm{H}_{2}$ ) were purchased from Nanocyl (Namur, Belgium) and utilized as reinforcing constituents for the resin blend matrix. A specially formulized styrene-free polyester resin and vinyl ester-epoxy resin (bisphenol A epoxy based) with 35 wt.\% of styrene were obtained from POLIYA Polyester, Turkey. Styrene emission agent BKY 740, purchased from Alton Chemie, Germany, was utilized to avoid the styrene evaporation from the hybrid resin during the polymerization reaction. Two layers of METYX non-crimp glass fabrics (NCFs) with a $\left[-45^{\circ} / 90^{\circ} /\right.$ $\left.+45^{\circ} / 0^{\circ}\right]_{s}$ stacking sequence from TELATEKS, Turkey, were employed as reinforcement to accomplish the composite laminates. Note that this stacking sequence was selected because interlaminar fracture tests are restricted in unidirectional $[0]_{n}$ composite laminates in which a delamination propagates between the plies all along the fiber direction appropriate to the coplanar assumption in fracture analysis [3-6]. The formulized resin blend was comprised of 25 wt.\% of styrene free polyester and $75 \mathrm{wt} . \%$ of vinyl ester. Styrene emission agent (1 wt.\%) was further added to the resin suspension prepared. To polymerize the resin suspensions, cobalt naphtanate (CoNAP) and methyl ethyl kethone peroxide (MEKP) were used as accelerator and initiator, respectively. This resin mixture was used to manufacture the corresponding glass fiber reinforced composite laminates.

\subsection{Preparation of resin suspensions}

Three-roll milling technique was conducted to prepare the resin suspensions to be used as matrix material for composites. In that manner, $0.1 \mathrm{wt}$ \% of MWCNT- $\mathrm{NH}_{2}$ were dispersed within styrene-free polyester resin via 3-roll milling technique followed by blending the collected resin staff with vinyl ester resin at a ratio of $1 / 3$. Please note that we used styrene - free polyester resin during 3-roll milling process to avoid the evaporation of styrene from the resin system due to heat evolved on the rolls. The detailed information regarding the preparation of CNT/resin system via 3-roll milling technique was given elsewhere $[17,18]$. 


\subsection{Manufacturing of composite laminates}

Composite laminates were manufactured using Vacuum Assisted Resin Transfer Molding (VARTM) technique. In this technique, preforms were placed on a flat tool coated with a release agent in order to ease the peeling of the composite part at the end. Preforms were then vacuum-infiltrated with the resin suspensions prepared. Fig. 1 depicts the schematic of the VARTM process and the catalyzed resin infiltrated composite parts allowed to cure at room temperature under vacuum. The cured parts were demolded and subsequently subjected to post-curing at $120^{\circ} \mathrm{C}$ for $2 \mathrm{~h}$. For the preparation of DCB and ENF specimens, a polyamide film was inserted in the mid-plane of the fabrics as a crack initiator prior to processing of the real composite parts.

\subsection{Mechanical characterization}

\subsubsection{Double cantilever beam test (DCB)}

Mode I interlaminar fracture toughness $\left(G_{1 \mathrm{l}}\right)$ of the base and the CNT modified composite laminates was measured based on DCB test according to ASTM D-5528-94a [19]. The DCB specimens were sectioned from the VARTM processed composite laminates with the length of $180 \mathrm{~mm}$ and a width of $25 \mathrm{~mm}$, using a diamond saw. Aluminum loading blocks were bonded to each side of the specimens such that the initial crack length, $a_{0}$, was set to $50 \mathrm{~mm}$ with reference to the inserted thin polyamide film. Fig. 2 shows a typical DCB test specimen and a photo under load during testing. The DCB specimens were tested at a crosshead speed of $5 \mathrm{~mm} / \mathrm{min}$ using a Schimadzu test machine with $5 \mathrm{kN}$ loading cell. At least five specimens were tested to evaluate the interlaminar response of the composite laminates with and without CNT modification. The experimental fracture data were recorded in the form of complete load/displacement curve as well as load/point displacement values which correspond to crack extension length.

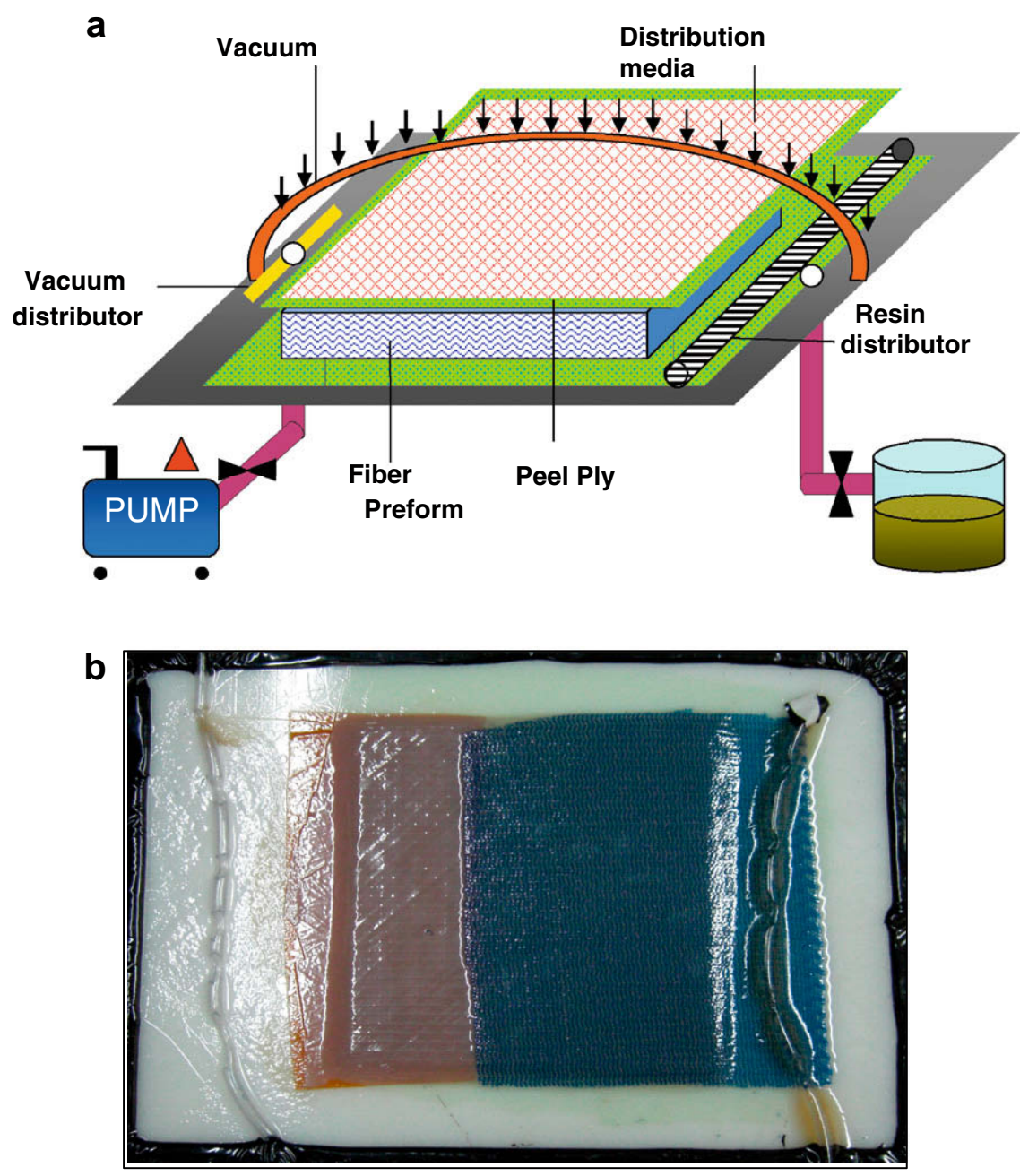

Fig. 1. (a) Schematic of the VARTM process and (b) the catalyzed resin infiltrated composite parts allowed to cure at room temperature under vacuum. 

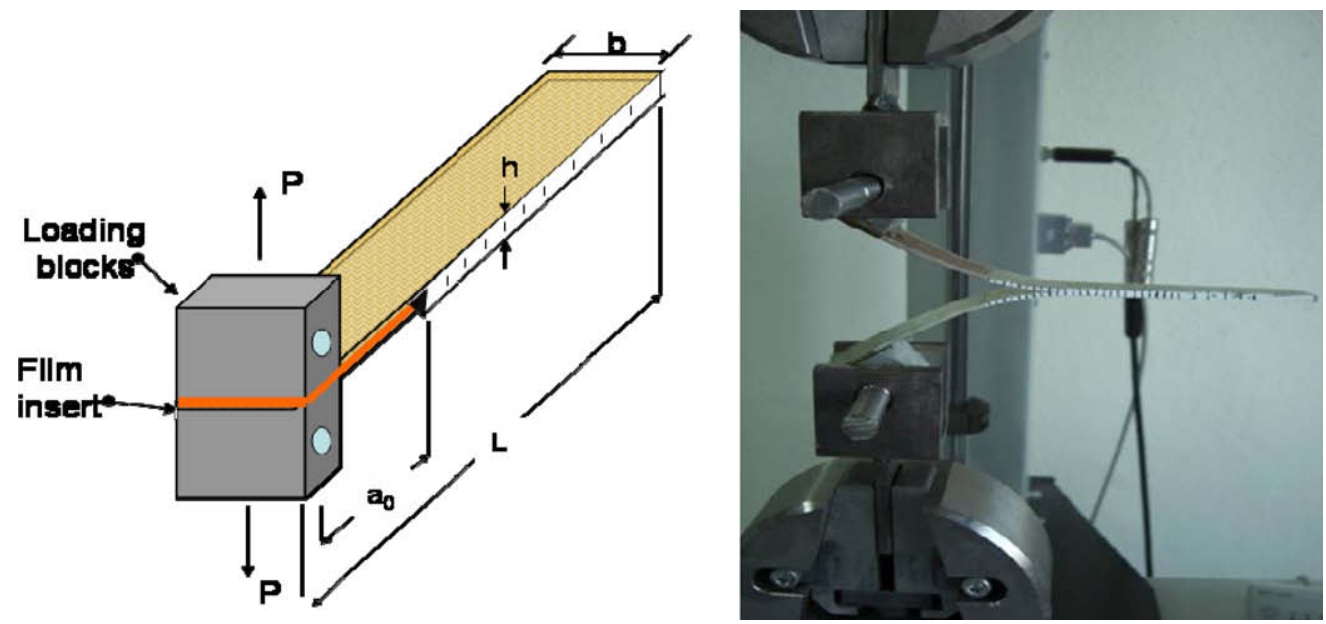

Fig. 2. Arrangement of a typical DCB test specimen and its photo under load during testing.

The critical strain energy release rate $\left(G_{c}\right)$ was computed based on the general formula linear elastic fracture mechanics (LEFM), as follows;

$$
G_{\mathrm{c}}=\frac{P_{\mathrm{c}}^{2}}{2 b} \frac{\partial C}{\partial a}=\frac{P_{\mathrm{c}} \delta}{2 b C} \frac{\partial C}{\partial a}
$$

where $P_{\mathrm{c}}$ is the critical load at which the crack propagates, $b$ is the width of the specimen, $C$ is the compliance, $\delta$ is the displacement and $a$ is the crack length.

The simple beam theory was then used to obtain the relationship between compliance and the crack length for a perfectly clamped at delamination front double cantilever beam. The Eq. (1) then becomes as the following [5,19];

$$
G_{\mathrm{Ic}}=\frac{3 P \delta}{2 b a}
$$

In practice, this expression overshoots the $G$ values because the relationship above is only valid for the ideal conditions assumed in the beam theory. In reality, correction is needed for large displacements, shear deformation, the stiffening effect of the end tabs, and for displacement and rotation at the delamination front. Some of these effects can be excluded by correcting the crack length. The crack length correction, $\Delta$ for each specimen is determined by plotting the cube root of the compliance, $(C)$ as a function of delamination length. This gives a straight line which intersects the crack length axis at $-\Delta$. Note that the compliance, $C$ is the ratio of load point displacement to its corresponding applied load $(\delta / P)$. $G_{\text {Ic }}$ values were then calculated based on the corrected LEFM (modified beam theory) formula using the equation below [19];

$$
G_{\text {Ic }}=\frac{3 P_{\mathrm{c}} \delta}{2 b(a+|\Delta|)}
$$

\subsubsection{End notched flexure test (ENF)}

The purpose of the ENF test was to determine the critical strain energy release rate in pure mode II loading ( $G_{\text {IIc }}$ ) of unidirectional composites. The ENF specimens were prepared in $120 \mathrm{~mm}$ long and $20-25 \mathrm{~mm}$ wide. This test was performed in a three point bend fixture with a span length of $100 \mathrm{~mm}$. Fig. 3 shows the ENF specimen geometry parameters and ENF specimen under load. The specimens were placed onto supports in such a way that the crack length-to-half span ratio $(a / L)$ is 0.5 at propagation of the crack. The load was applied with a displacement control of $1 \mathrm{~mm} / \mathrm{min}$. [5]. At least five specimens were tested for ach type. The ENF specimen produces shear loading at the crack tip without introducing excessive friction between the crack surfaces. However, the crack propagation is inherently unstable under displacement control. During the experiment, the load versus cross head displacement was recorded. Once the crack starts propagating, a sudden load drop was observed and the test was terminated. The ultimate load recorded and its corresponding point beam deflection measured from the cross head displacement corrected for the machine compliance were used in the data reduction. Simple beam theory allows the calculation of the compliance, $C$, which can be expressed for a ENF specimen as below [6];

$$
C=\frac{2 L^{3}+3 a^{3}}{8 E_{1} b h^{3}}
$$

where $E_{1}$ is the flexural modulus and $h$ is one half the total thickness of the beam, (in other words, the thickness of each subbeam of the delaminated region). If $C$ value is inserted into Eq. (1), the strain energy release rate for an ENF specimen can be obtained as follows; 

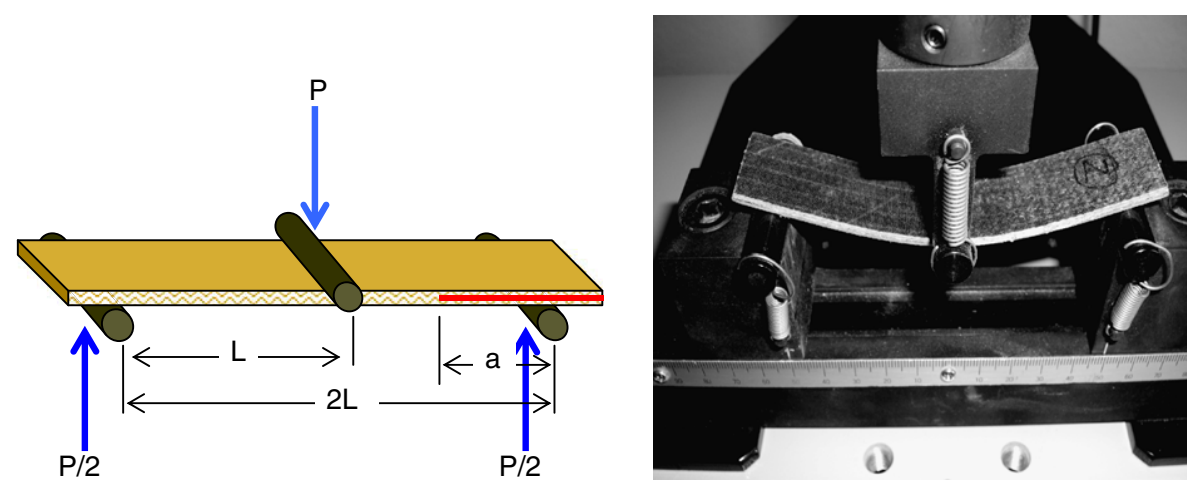

Fig. 3. ENF specimen geometry and ENF specimen under load.

$$
G_{\text {IIC }}=\frac{9 P_{\mathrm{c}}^{2} a^{2}}{16 E_{1} b^{2} h^{3}}=\frac{9 P_{\mathrm{c}}^{2} C a^{2}}{2 b\left(2 L^{3}+3 a^{3}\right)}
$$

$C$ is also the ratio of load point displacement to its corresponding applied load $(\delta / P)$. $G_{\text {IIC }}$ can be finally rewritten as in the equation below [5-7];

$$
G_{\text {IIc }}=\frac{9 P_{\mathrm{c}} \delta a^{2}}{2 b\left(2 L^{3}+3 a^{3}\right)}
$$

\subsubsection{Short beam shear test (SBS)}

The interlaminar shear strength (ILSS) of the base and CNT modified composite laminates was measured using the short beam shear (SBS) test method according to ASTM D-2344 [20]. This test method involves loading a beam under three-point bending in such a way that an interlaminar failure is induced along the mid-plane rather than a tensile failure on the bottom surface of the beam. In this manner, the specimens of $21 \mathrm{~mm}$ in length and $10 \mathrm{~mm}$ in width were sectioned from the composite laminates. The length to thickness ratio and span to thickness ratio were kept constant at 7 and 5 , respectively. The crosshead speed was set to $5 \mathrm{~mm} / \mathrm{min}$. At least six specimens from each set were tested using universal testing machine with $5 \mathrm{kN}$ loading cell and load at break was recorded. The interlaminar shear strength $\left(\tau_{\max }\right)$ was calculated based on the Equation given below (3)

$$
\tau_{\max }=0.75 \frac{P}{b d}
$$

where $P$ is the maximum applied load, $b$ is the width and $d$ is the thickness of the specimens.

\subsubsection{Microscopic investigation}

A Nikon Optical microscopy was used to evaluate the distribution of CNTs across the composite part. Philips SEM at $3 \mathrm{kV}$ voltages was also conducted to examine macro-scale fracture failure modes that occurred within the specimens under mechanical loading. The effects of carbon nanotubes on the damage mechanisms of the composite laminates were then evaluated.

\section{Results and discussion}

\subsection{Dispersion of nanotubes and VARTM processing}

MWCNT-NH $\mathrm{N}_{2}$ (0.1 wt.\%) was dispersed within the resin system using a high shear mixing process called 3-roll milling technique as described above. This method was already found to be better in dispersion of CNTs within thermosetting resin systems as compared to other common methods such as sonication and mechanical stirring [11,17]. Moreover, it must be emphasized that incorporation of CNTs significantly increases the viscosity of the corresponding resin blend, which causes difficulties during the VARTM processing. In our former study [18], it was revealed based upon rheological examinations that transition from liquid like to pseudo-solid like behavior occurs with the resin suspensions containing 0.3 wt.\% of MWCNTs and MWCNT- $\mathrm{NH}_{2}$. It was also revealed that resin suspensions with CNT additives exhibit shear thinning behavior, regardless of type or content of nanotubes. On the basis of the previous findings, the content of nanotubes to be incorporated into the resin system for the present study was selected as $0.1 \mathrm{wt} . \%$, which is lower than rheological threshold value of $0.3 \mathrm{wt} . \%$. One reason of this selection lies in avoiding extremely high viscosity value of the resin blend for manufacturing of composite laminates via VARTM process. The other one is to prevent CNT agglomerates within matrix resin due to the huge specific surface area of nanotubes that leads to enormous attractive forces to occur between the individual tubes. A comprehensive 
discussion with a particular emphasis on the problems regarding the dispersion of carbon nanotubes within the resin systems used in this study was already addressed elsewhere [17,18].

Fig. 4 shows the photos of CNT modified hybrid resin infiltrated composite laminates cured at room temperature under vacuum and the corresponding optical micrograph of the mid-plane distribution of CNTs at the inlet, in the middle and at the vent points of the composite laminates. It seems that nanotube distribution at mid-plane of the composite laminates across its length is generally adequate. However, the specimens taken from nearby the vent region contained relatively low amount of nanotubes. Fan et al. [21] investigated the role of glass fabric porous media effect on the dispersion of MWCNTs during flow of MWCNTs modified vinyl ester resin injected into the mold cavity containing glass fiber mats. They observed that the resin suspensions flow faster between the fiber tows than within the fiber tows. After some experimental trials, they

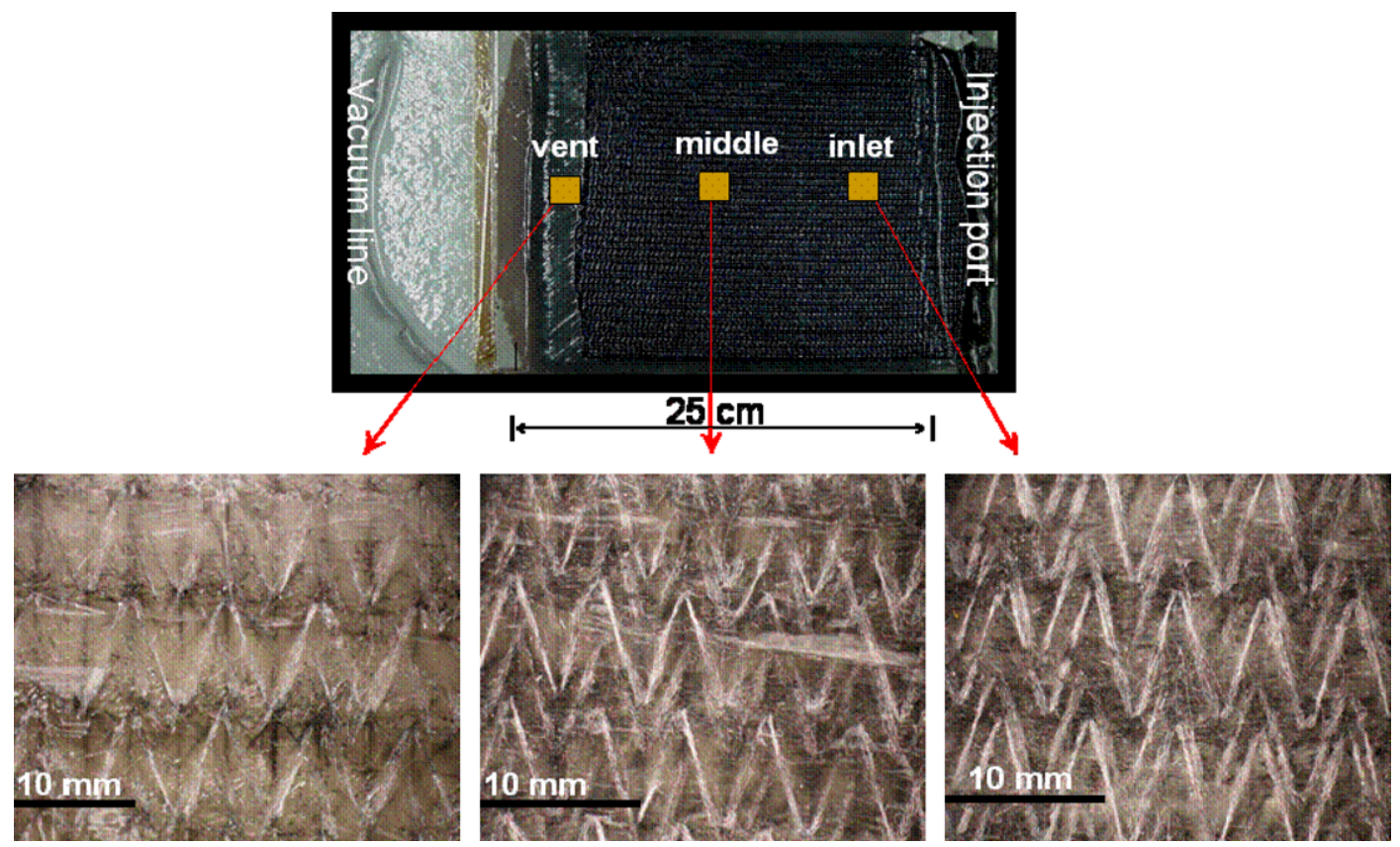

Fig. 4. Nanotube modified hybrid resin infiltrated composite laminates allowed to cure at room temperature under vacuum and optical micrograph of the mid-plane dispersion of the nanotubes at the inlet, in the middle and at the vent of the cured laminate.

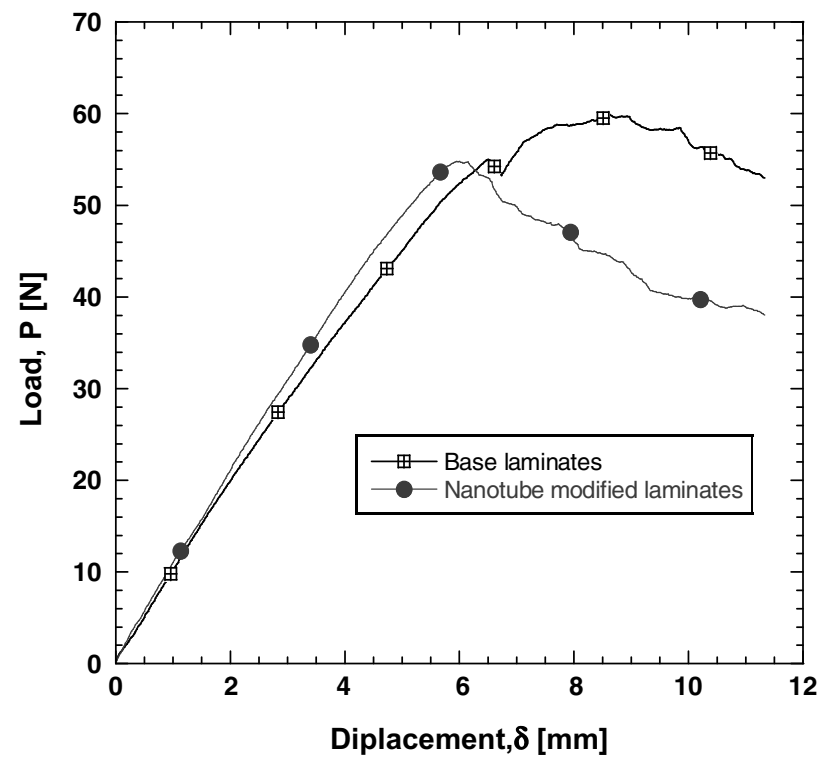

Fig. 5. Representative load-deflection curves of the DCB tests for the base and nanotube modified laminates. 

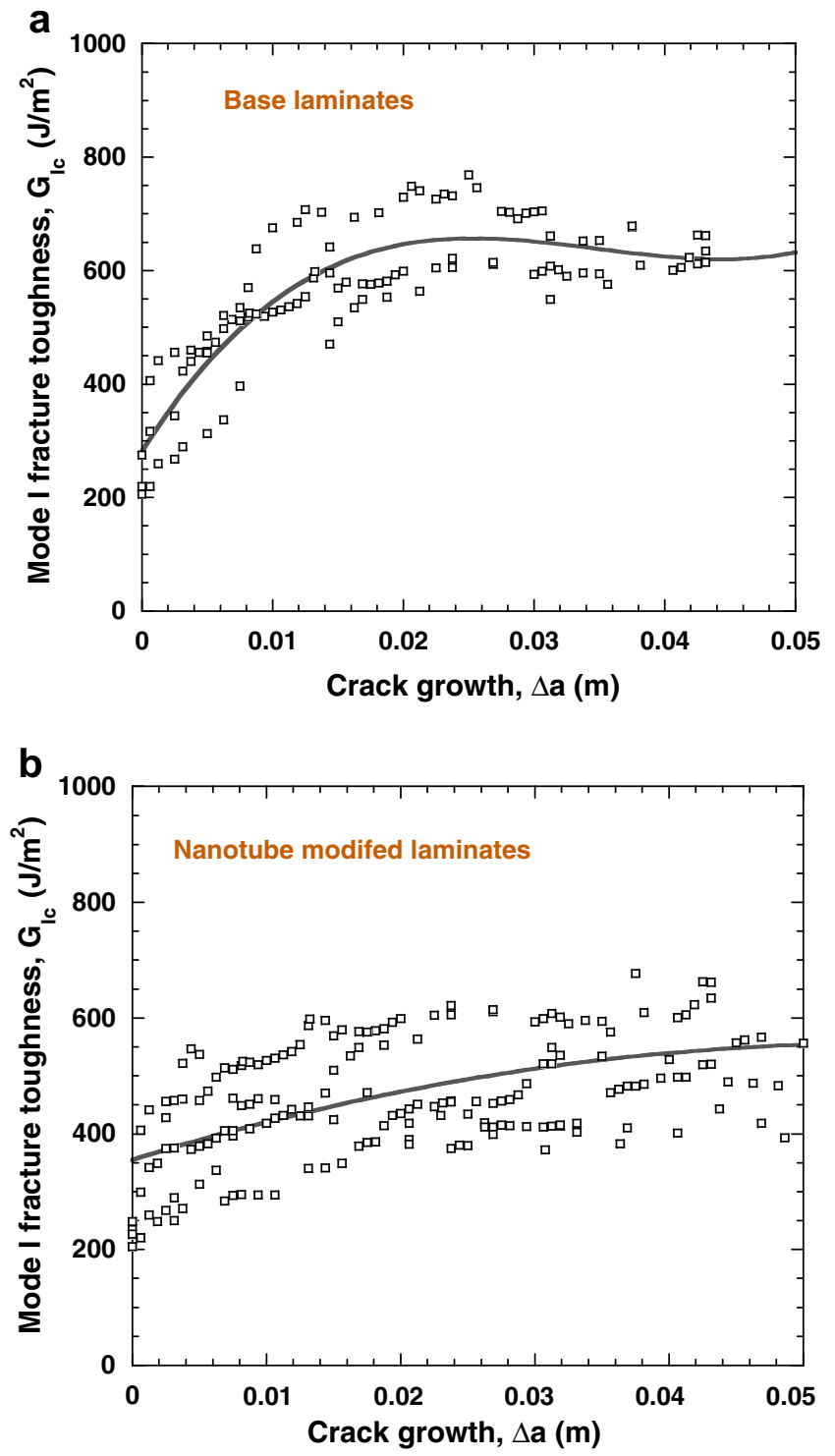

Fig. 6. (a) Mode I fracture toughness value of the base and (b) nanotube modified composite laminates with respect to crack growth, respectively.

concluded that the shear rate which occurs during resin flow disentangle very condensed aggregates into smaller ones due to a filtering effect, which is, however, insufficient to separate relatively tiny aggregates into individual nanotubes within the suspension. From that point of view, one could say hypothetically that uniform small sized agglomerates of CNTs within resin matrix prior to the VARTM process would be most beneficial to accomplishing an overall homogeneous distribution of CNTs within the fiber tows of glass fabrics. This may explain the appearance of relatively poor nanotubes impregnated fiber bundles located at the mid-plane of the fabric closer to the vent region. Another point is that the presence of both \pm 45 angle plies in the glass fabric decreased the fiber permeability, which makes it difficult for the resin to fill the part with uniform flow front.

\subsection{Mode I fracture toughness of the composite laminates}

Fig. 5 shows the representative load-deflection curves of the DCB specimens for the base and CNT modified laminates. As seen in the figure, both the base and CNT modified laminates show a well defined linear load-displacement relationship up to the point of crack initiation, after which they demonstrate distinct crack growth mechanism. In details, crack propagates within the base laminates by small incremental jumps without causing any sharp decrease in the load values. This indicates that the stick-slip crack growth mechanism is dominant for the base laminates across the non-linear region. However, steady crack growth mechanism within the CNT modified laminates is visible such that no significant rise or decrease are 


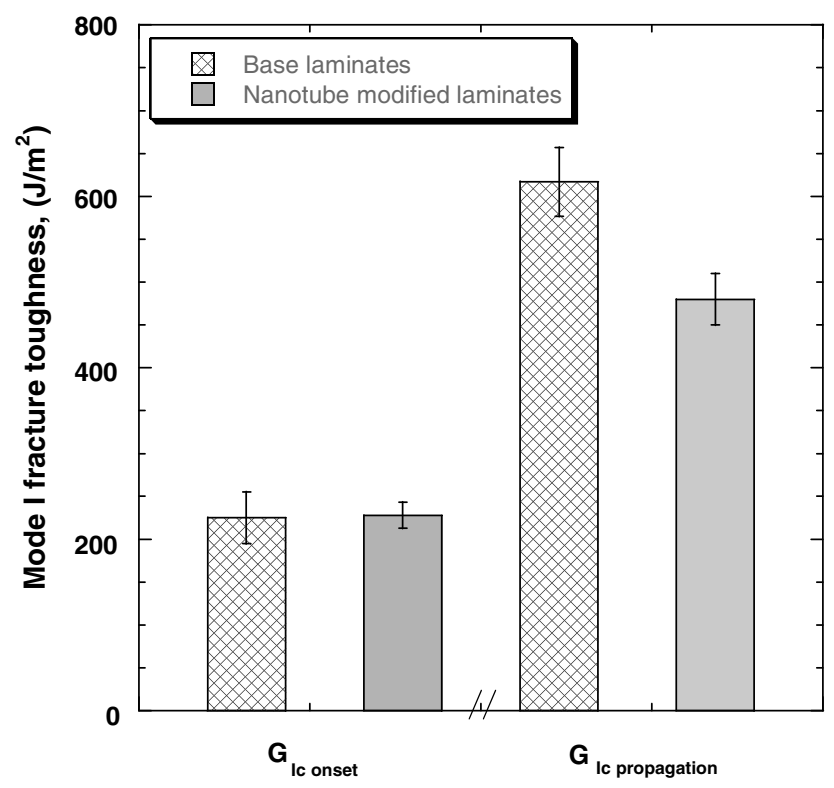

Fig. 7. Mode I onset and propagation fracture toughness values of the base and nanotube modified composite laminates together.

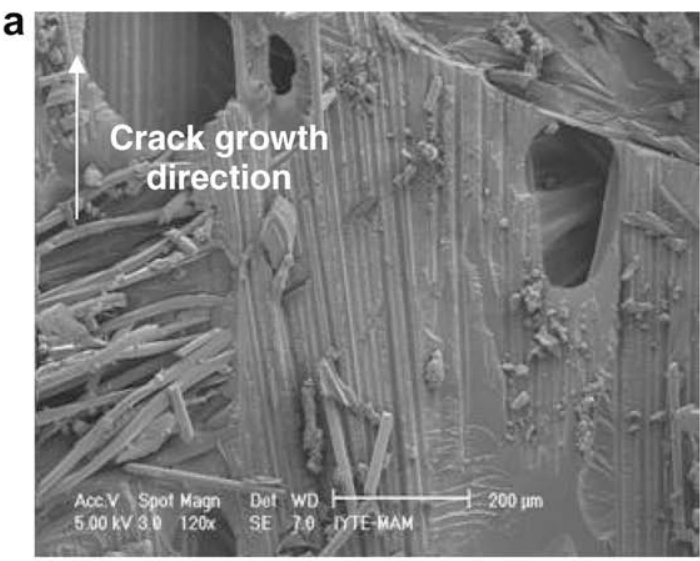

b

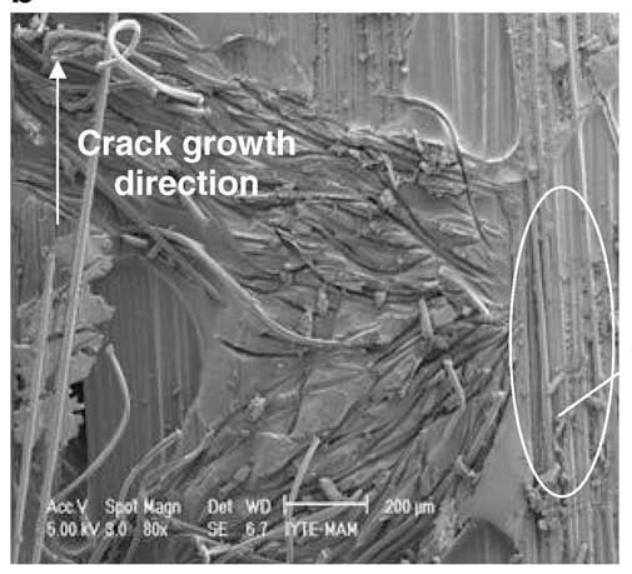

C

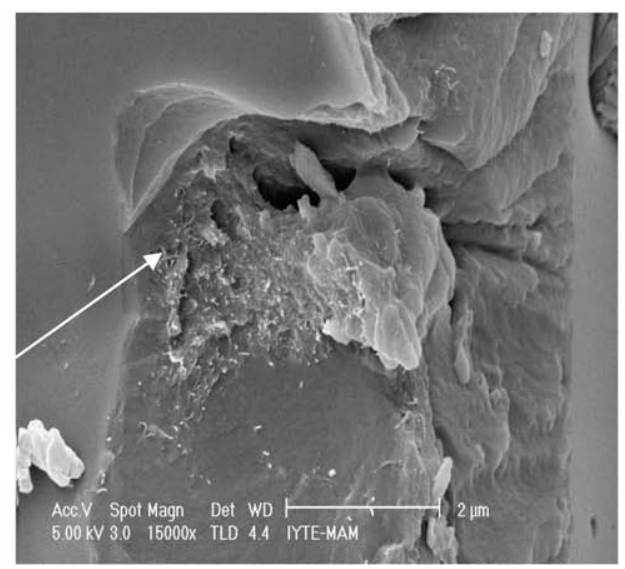

Fig. 8. SEM micrographs showing the mid plane fracture surfaces of DCB specimens (a) with and (b) without CNT modification. Fig. 8 (c) depicts a magnified region of Fig. 8 (b). 
observed for the load values with respect to displacement. In principle, at the first loading increment, the delamination starts propagating from the tip of the film insert (crack starter) without taking any influence from fiber bridging (on-set values). In other words, the onset values refer to the critical load and displacement associated with the first deviation from the linear response in the corresponding curve. As the crack further propagates, bridged fibers may crack or be pulled out from the matrix due to the progressively separated crack surfaces, which gives rise to the apparent fracture toughness [4-7]. Once equal number of bridged fibers is achieved per unit crack area during crack propagation, steady state fracture toughness is eventually supposed to occur, which is commonly referred to as propagation fracture toughness value [5].

Fig. $6 a$ and b shows mode I interlaminar fracture toughness $\left(G_{\mathrm{IC}}\right)$ values of the base and nanotubes modified composite laminates as a function of crack growth, respectively. The solid curves on the both graphs represent the general trend of the fracture toughness for the corresponding laminate as a function of crack extension. Dissimilar to behavior of the nanotube modified composite laminates within the first stage of crack extension, the $G_{I C}$ of the base composite laminates rise sharply followed by a moderate increase for further crack extension. At about $25 \mathrm{~mm}$ extension, steady state fracture toughness

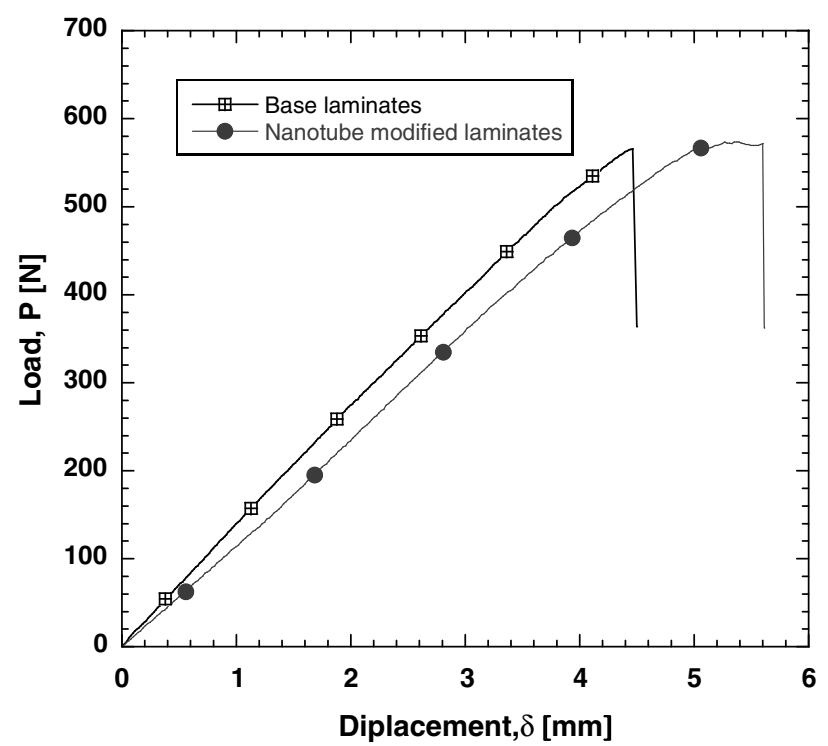

Fig. 9. Representative load-deflection curves of the ENF tests for the base and nanotube modified laminates.

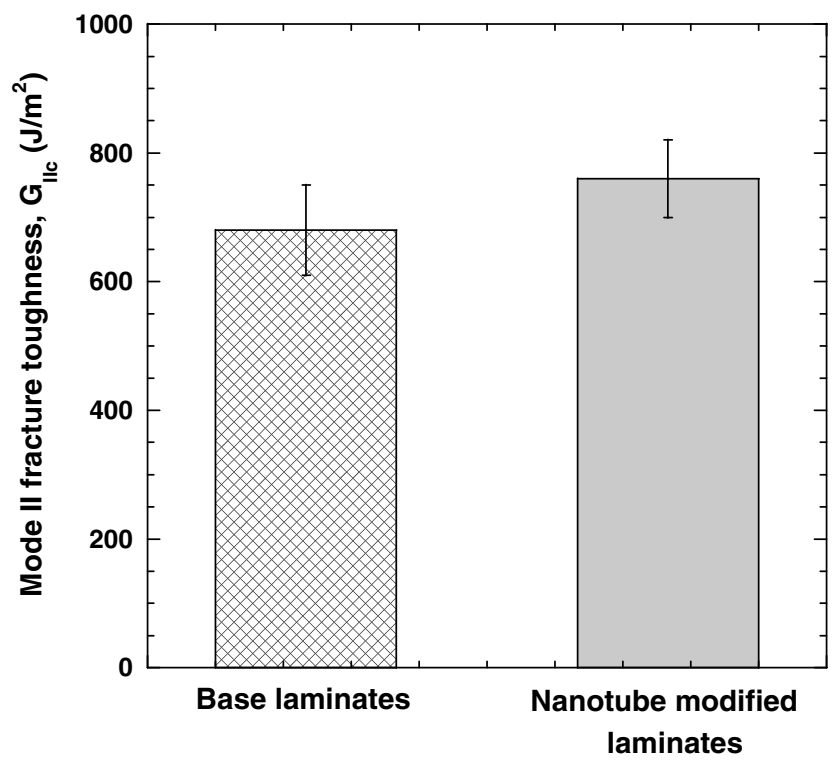

Fig. 10. Mode II fracture toughness of the base and nanotube modified composite laminates together. 
(propagation) was observed for the base composite laminates, while this value for the CNT modified composite laminates switched to $35 \mathrm{~mm}$, which shows the consistency with their load deflection curves. The presence of CNTs within the glass fiber bundles may alter the adhesion mechanism of two adjacent glass plies at the laminate mid-plane where the delamination takes place. Fiber bridging is vastly critical to the propagation toughness values of the composites because the instant increase in apparent fracture energy is highly associated with de-bonding of the larger surface area of the bridged fibers and breaking of these fibers. Fiber nesting is one major source of fiber bridging [5-8]. In our case, CNTs randomly oriented in the matrix resin would be capable of limiting fiber nesting, just diffusing into fiber tows and filling the gaps between fiber bundles by accumulating around them. This may be the reason for inconsistency in the behavior of base and the CNT modified laminates during the extensions of crack at which the propagation of the fracture begins.

Fig. 7 depicts the interpreted onset and propagation fracture toughness values of the base and nanotubes modified composite laminates. As seen in the figure, there is no significant difference in the onset fracture toughness values between the base and nanotubes modified composite laminates. However, the propagation fracture value of the base composite laminates

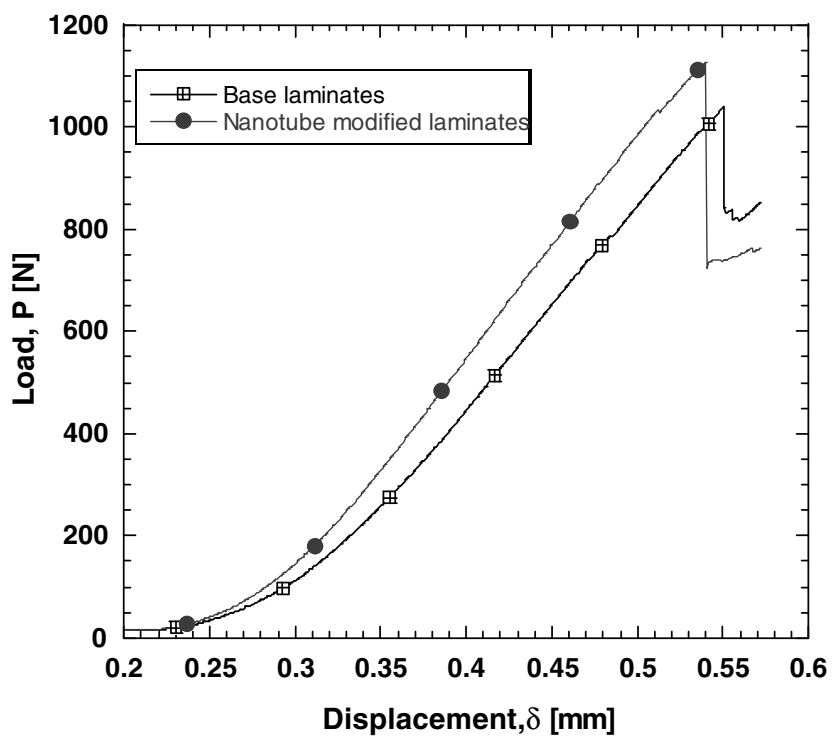

Fig. 11. Representative load-deflection curves of the SBS tests for the base and nanotube modified laminates.

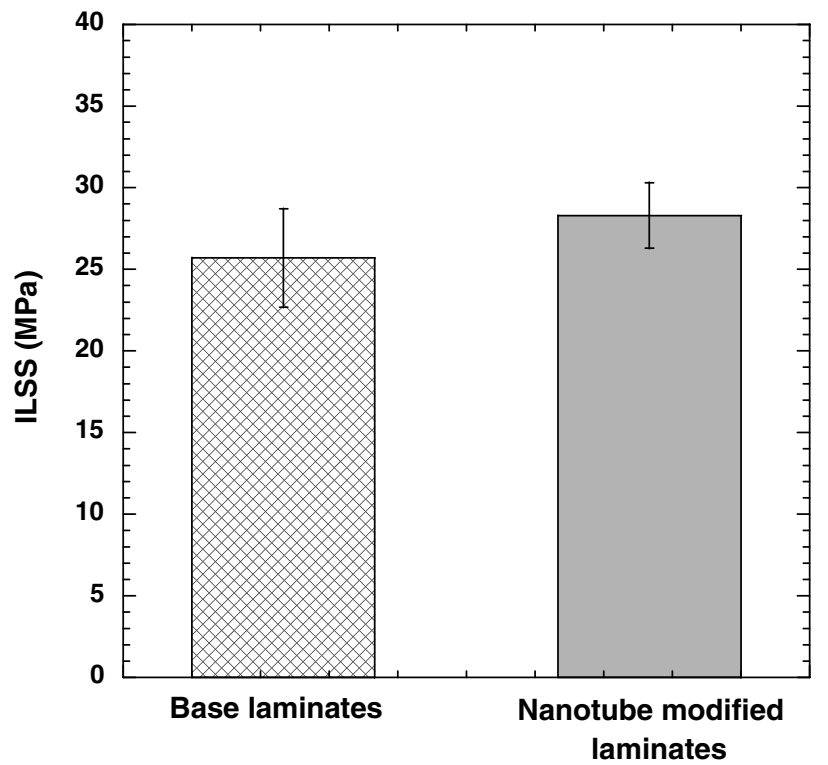

Fig. 12. Interlaminar shear strength of the base and nanotube modified composite laminates together. 
was found to be $40 \%$ higher than that of nanotube modified composite laminates. Existence of no significant difference in the on-set fracture toughness values between the base and CNT laminates supports our conclusion that presence of CNTs hinder the fiber bridging effects in a considerable manner, thus reducing the degree of fiber nesting. Fig. 8a and b are the SEM micrographs showing the mid plane fracture surfaces of the DCB specimens without and with CNT modification, respectively. Fig. $8 \mathrm{c}$ is a magnified image of a local area on Fig. 8b. The image shows individual glass fibers coated with CNT-rich matrix resin. As seen in the figures, the major failure mechanism is the debonding of the fiber matrix interface and matrix fracture. It was observed that the de-bonding is less extensive for the composites with CNT modification. This implies that CNTs supress the degree of fiber bridging to some extent, which leads to lower $G_{1 \mathrm{c}}$ propagation toughness values for the composites modified with CNTs.

Fig. 9 shows the representative load-deflection curves of the ENF tests for the base and nanotube modified laminates. The calculated mode II fracture toughness values of the base and nanotubes modified composite laminates were depicted in Fig. 10. As mentioned earlier, the ENF test measures only the initiation fracture toughness. As seen in the figure, mode II fracture toughness values of the nanotube modified composite laminates are slightly higher (8\%) than those of the base composite laminates. Under mode II loading, fiber bridging does not occur. Two other important mechanisms; friction and hackles are responsible for the energy absorption. Unlike DCB specimens that exhibit continuous crack growth along the fiber/matrix interface, ENF specimens show discontinuous crack growth by micro-crack coalescence which leads to many hackles to occur at the fracture surface. It seems that nanotube bundles act as rigid fillers which arrest the crack, preventing or delaying the expansion of micro-cracking within the matrix rich interface area. So, it is realistic to anticipate a higher amount of hackles present at the fracture surface of the CNTmodified composite laminates as compared to that of the base composite laminates. This leads to a relatively high energy absorption by friction in nanotubes modified composite laminates. In other words, nanotubes may improve the adhesion between the interlayer and the adjacent composite layers at the same time.

Fig. 11 gives representative load-deflection curves of the SBS tests for the base and nanotube modified laminates. Fig. 12 shows the ILSS of the base and nanotubes modified composite laminates together. It was found that the use of the modified hybrid resin significantly increased (11\%) the interlaminar shear strength of the composite laminates. The average value of the base composite laminates is 25.7 MPa, while this value increased up to 28.6 MPa for the CNT modified composite laminates. This may be attributed to larger tensile strength, modulus and fracture toughness values of a CNT modified polymer matrix as compared to those for neat hybrid resin, as addressed in details in our earlier study [17]. Fig. 13a-d show the midplane fracture surface of a failed short beam shear specimen taken from the CNT modified composite laminates. Note that Fig. 9b and $d$ are the higher magnification of Fig. 9a and c, respectively. CNT rich regions on the fracture surfaces are also visible on the micrographs. From that point of view, a strengthened region at interface may form due to accumulation of
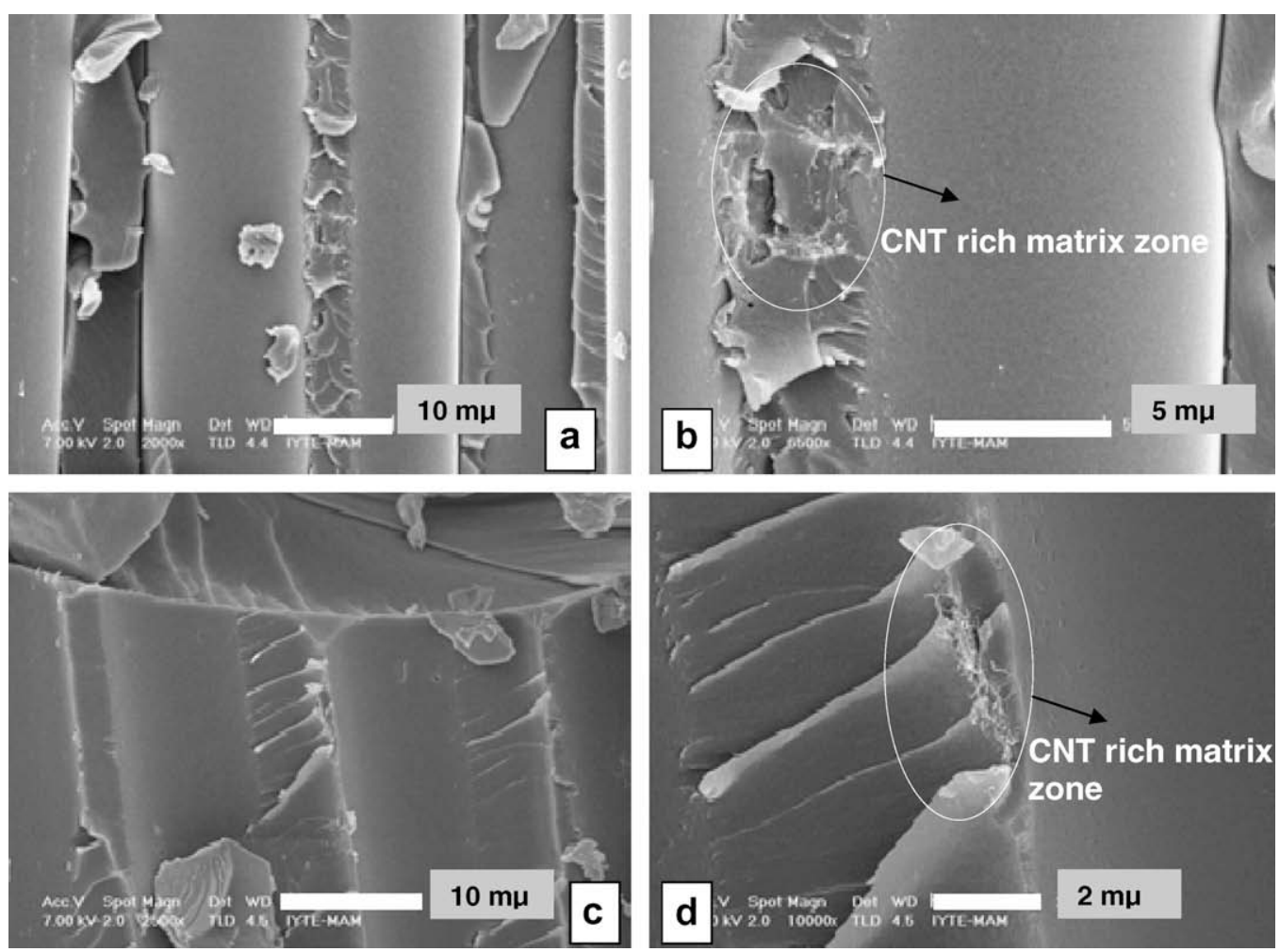

Fig. 13. SEM micrographs of the mid-plane fracture surface of a failed short beam shear specimen taken from the CNT modified composite laminates. The images of $13 \mathrm{~b}$ and $\mathrm{d}$ are from regions on $13 \mathrm{a}$ and $\mathrm{c}$ at higher magnifications, respectively. 
nanotubes around the glass fibers. In other words, nanotube bundles and aggregates smaller than glass fiber tows may alter the interfacial strength, acting as additional reinforcement at the interlaminar region between polymer matrix and glass fiber. This leads to relatively large interlaminar shear strength values to be obtained from the nanotube modified composite laminates.

\section{Conclusions}

In this study, the matrix dominated mechanical properties of long glass fiber reinforced composite laminates, including mode I, mode II fracture toughness and interlaminar shear strength of glass fiber/carbon nanotube (CNT) modified vinyl ester-polyester based composites were investigated. In that manner, the base and nanotubes modified composite laminates were successfully manufactured via vacuum assisted resin transfer molding (VARTM) process, using E-glass fiber non-crimp fabrics with a $\left[-45^{\circ} / 90^{\circ} /+45^{\circ} / 0^{\circ}\right]_{s}$ stacking sequence. To produce hybrid resin to be utilized as matrix material during VARTM process, $0.1 \mathrm{wt}$.\% of MWCNT- $\mathrm{NH}_{2}$ were first dispersed within specially synthesized styrene-free polyester resin, conducting 3-roll milling technique followed by blending the collected resin suspension with vinyl ester resin. In consequence, the mode I interlaminar fracture toughness value of the nanotubes modified composite laminates was found not to be significantly affected, while their mode II fracture toughness value was found to be about $8 \%$ higher compared to the base laminate. It was also observed that the interlaminar shear strengths of the nanotubes modified composite laminates was $11 \%$ higher than those of the base composite laminates. As a general statement, despite a pronounced increase in the matrix toughness, it seems that it is still a big challenge to transfer the improved nanotube modified matrix properties such as fracture toughness or shear strength into conventional long fiber composites due to some difficulties with composite processing. Overall, a stronger interfacial bonding and a higher level of uniform CNT distribution within and around the glass fiber tows are the key parameters to accomplish the desired properties in their resultant composite parts.

\section{Acknowledgement}

The authors acknowledge TUBITAK of Turkey and JULICH of Germany for financial support (under Julich 5 Project, 103M048).

\section{References}

[1] Alveraz V, Bernal CR, Fonrtini PM. The influence of matrix chemical structure on the mode I and II interlaminar fracture toughness of glass-fiber/epoxy composites. Polym Compos 2003;24:140-8.

[2] Tanoglu M, Seyhan AT. Investigating the effects of a polyester performing binder on the mechanical and ballistic performance of E-glass fiber reinforced polyester composites. J Adhes Sci Technol 2003;23:1-8.

[3] Zhu J, Imam A, Crane R, Lozano K, Khabashesku VN, Barrera EV. Processing a glass fiber reinforced vinyl ester composite with nanotube enhancement of interlaminar shear strength. Compos Sci Technol 2007;67:1509-17.

[4] Lee SM. Mode II delamination failure mechanisms of polymer matrix composites. J Mater Sci 1997;32:1287-95.

[5] Albertsen H, Ivens J, Peters P, Wevers M, Verpoest I. Interlaminar fracture toughness of CFRP influenced by fiber surface treatment: Part 1 Experimental results. Compos Sci Technol 1995;54:133-45.

[6] Lee JJ, Lim JO, Huh JS. Mode II interlaminar fracture behavior of carbon bead-filled epoxy/glass fiber hybrid composite. Polym Compos 2000;21:343-52.

[7] Srivastana VK, Hogg PJ. Moisture effects on the toughness, mode I and mode II of particles filled quasi isotropic glass fiber reinforced polyester resin composites. J Mater Sci 1998;33:1129-36.

[8] Frankland SJV, Caglar A, Brenner DW, Griebel M. Molecular simulation of the influence of chemical cross-links on the shear strength of carbon nanotube-polymer interfaces. J Phys Chem 2002;B106:3046-54.

[9] Gojny FH, Schulte K. Functionalization effect on the thermo-mechanical behavior of multiwalled carbon nanotube/epoxy composites. Compos Sci Technol 2004;34:2303-8

[10] Gryschuck O, Kocsis JK, Thomann R, Kanya Z, Kiricsi I. Multiwalled carbon nanotube modified vinyl ester and vinyl ester- based hybrid resins. Compos A Appl S 2006;37:1252-61.

[11] Gojny FH, Wichmann MHG, Fiedler B, Schulte K. Influence of different carbon nanotubes on the mechanical properties of epoxy matrix composites- A comparative study. Compos Sci Technol 2005;65:2300-13.

[12] Gojny FH, Nastalczyk J, Roslaniec Z, Schulte K. Surface modified multiwalled carbon nanotubes in CNT/epoxy composites. Chem Phys Lett 2003;21:820-4.

[13] Gojny FH, Wichmann MHG, Köpke U, Fiedler B, Schulte K. Carbon nanotube-reinforced epoxy composites: enhanced stiffness and fracture toughness at low nanotube content. Compos Sci Technol 2004;34:2363-71.

[14] Gojny FH, Wichmann MHG, Fiedler B, Schulte K. Influence of different carbon nanotubes on the mechanical properties of epoxy matrix composites- A comparative study. Compos Sci Technol 2005;65:2300-13.

[15] Gojny FH, Wichmann MHG, Fiedler B, Bauhofer W, Schulte K. Influence of nano-modification on the mechanical and electrical properties of conventional fiber reinforced composites. Compos A Appl S 2005;36:1525-35.

[16] Wichmann WHG, Sumfleth J, Gojny FH, Quaresimin M, Fiedler B, Schulte K. Glass fiber reinforced composites with enhanced mechanical and electrical properties - benefits and limitations of a nanoparticle modified matrix. Engng Fract Mech 2006;73:2346-59.

[17] Seyhan AT, Gojny FH, Tanoglu M, Schulte K. Critical aspects related to processing of carbon nanotube/unsaturated thermoset polyester nanocomposites. Eur Polym 2007;J43:374-9.

[18] Seyhan AT, Gojny FH, Tanoglu M, Schulte K. Rheological and dynamic-mechanical behavior of carbon nanotube/vinyl ester-polyester suspensions and their nanocomposites. Eur Polym 2007;j43:2836-47.

[19] ASTM Standard D5528-94a, Test Method for Mode I Interlaminar Fracture Toughness of Unidirectional Fiber-Reinforced Polymer Matrix Composites, American Society for Testing and Materials, West Conshohocken, PA, 2001.

[20] ASTM D 2344-00, Test Method for Short Beam Strength of Polymer Matrix Composite Materials and their Laminates by Short-Beam Method, American Society for Testing and Materials, West Conshohocken, PA, 2001.

[21] Fan Z, Hsiao HT, Advani SG. Experimental investigation of dispersion during flow of multi walled carbon nanotube/polymer suspension in fibrous porous media. Carbon 2004;42:871-6. 